\title{
Coffee Market Liberalisation and the Implications for Producers in Brazil, Guatemala and India*
}

\author{
Bill Russell, Sushil Mohan, and Anindya Banerjee
}

\begin{abstract}
The standard approach to modelling the relationship between world and producer prices of coffee does not incorporate the effects of changing government policies and market structures. These changes have led to large structural breaks in the relationship between the prices implying the standard estimates are biased. We model coffee prices in Brazil, Guatemala and India allowing for the structural breaks and show that the liberalisation of coffee markets has benefited producers substantially both in terms of a higher share of the world price of coffee and higher real prices. This suggests that calls to re-regulate coffee markets may be misplaced. JEL Classification: Q11, Q17, Q18, C32, C52, F13, F14
\end{abstract}

Before the 1990s, unilateral and multilateral interventions in coffee markets were common. The governments of most coffee-producing countries considered regulation of coffee marketing and pricing necessary because of coffee's importance as a source of foreign exchange and government revenue. ${ }^{1}$ For major coffee-producing countries such as Brazil and Colombia the main objective for regulation was to raise world coffee prices. Countries also used regulation to maintain fixed producer prices so as to shield coffee producers (hereafter

* Bill Russell (corresponding author), Economic Studies, School of Business, University of Dundee, Dundee DD1 4HN, United Kingdom. +44 1382385165 (work phone), +44 1382384691 (fax), email brussell@brolga.net. Sushil Mohan, Economic Studies, School of Business, University of Dundee, United Kingdom. Anindya Banerjee, Department of Economics, Birmingham Business School, University of Birmingham, United Kingdom. We would like to thank David Hendry and Hassan Molana for their helpful advice, Ivan Carvalho, Denis Seudieu and Martin Wattam from the International Coffee Organization for help in providing the data, and Tom Doan and Pierre Perron for graciously making available the programmes for estimating structural breaks. A Supplementary Appendix to this article is available at http://wber.oxfordjournals.org and http://billrussell.info. The data are available at http:// billrussell.info.

1. Unless specified otherwise, 'coffee' means green (raw or un-roasted) beans and coffee prices imply prices of green beans. Coffee producers include growers and/or semi-processors, who sell their coffee as cherries, parchment or green beans. If producers sell their coffee as cherry or parchment, the prices are converted to green beans by using a 'green bean equivalent'.

THE WORLD BANK ECONOMIC REVIEW, VOL. 26, NO. 3, pp. 514-538

doi:10.1093/wber/lhr055

Advance Access Publication January 10, 2012

(C) The Author 2012. Published by Oxford University Press on behalf of the International Bank for Reconstruction and Development / THE WORLD BANK. All rights reserved. For permissions, please e-mail: journals.permissions@oup.com 
referred to as producers) from price fluctuations and assured them a minimum price. $^{2}$

At the multilateral level the interventions generally took the form of regulation of export supply and prices. The first International Coffee Agreement (ICA) was signed in 1962 by the major coffee producing (exporting) and consuming (importing) countries. According to its regulatory provisions, basic export quotas were allocated to each of the exporting member countries for export to importing member countries and they were tightened if international coffee prices fell below a particular level and loosened when they rose above that level. The monitoring requirements of the ICA supported the domestic regulation of coffee markets in coffee-producing countries to ensure compliance with quota restrictions. ${ }^{3}$ The ICA was undermined by some member countries distributing their exports at lower prices through non-member countries, the inability to agree on quotas and the continuing fragmentation of the geography of production. Quotas were operational between October 1963 to December 1973, October 1980 to March 1986, and November 1987 to July 1989 (ICO, 1989). The agreement was suspended in 1989.

The suspension of the International Coffee Agreement (ICA) in 1989 and broader economic reforms including exchange-rate reforms in most developing countries in the late 1980 s resulted in most coffee-producing countries liberalising their coffee sector by replacing state-controlled marketing systems with markets run by private agents. The pace and scope of liberalisation has varied across countries but has led to a more competitive international coffee market in which producer prices reflect more accurately the domestic and international market conditions.

In terms of their impact on producer welfare the interventions are generally regarded as unsuccessful. The cost of reduced volatility seemed too high given that the administered prices were usually far below the certainty equivalent that would be accepted by producers. ${ }^{4}$ Jarvis (2005) and Mehta and Chavas (2008) find that the interventions resulted in high levels of rent seeking by a range of beneficiaries including bureaucrats, intermediaries such as coffee marketing boards and foreign importers, but not by producers. The accruing of these economic rents to intermediaries in the coffee supply chain creates a larger margin between the international and producer prices of coffee resulting in a lower share of the international price of coffee going to producers.

However, some commentators do not accept these assertions and raise concerns on the effects of these reforms on the real price of coffee received by producers. They feel that the principal beneficiaries of liberalisation have been

2. See Akiyama (2001).

3. For a brief description of coffee market interventions see Supplementary Appendix S1 available at http://wber.oxfordjournals.org and http://www.billrussell.info. See also Raffaeli (1995), Gilbert (1996), Bates (1997), McIntire and Varangis (1999), Jerome and Ogunkola (2000), Akiyama (2001), Varangis et al. (2002) and Winter-Nelson and Temu (2002).

4. See Akiyama et al. (2001), Krivonos (2004) and Anderson et al. (2008). 
coffee roasters and international traders who are able to capture all the monopoly rents and dictate the prices they are willing to pay to producers. ${ }^{5}$ Lately there have been calls for a return to some form of coffee market interventions or regulations on the grounds that the liberalisation of coffee markets has not improved the plight of producers. ${ }^{6}$

To evaluate if producers were better or worse off due to the regulation and interventions in coffee markets requires us to compare the actual returns they received with some counter-factual return that they would have received in unregulated markets. The terminal (or international) price of coffee has not been directly regulated or administered over the last four decades. ${ }^{7}$ Consequently, if the 'law of one price' between the terminal and producer prices of coffee holds then we can use the terminal price to calculate the corresponding un-regulated producer price of coffee. This allows us to compare the actual returns to producers with the return that producers would have received in an un-regulated market.

Unfortunately, the recent extensive literature does not provide unambiguous empirical evidence in support of the 'law of one price'. The results depend on the level of aggregation of the data and the methods employed to 'test' the relationship between prices in different markets. For example, the work on commodity markets by Ardeni (1989) and Baffes (1991) provide mixed evidence on accepting the 'law' while Mundlak and Larson (1992), Michael et al. (1994), Vataja (2000) and Batista and da Silveira (2010) provide evidence that supports the 'law'. Moreover, this literature mostly focuses on the 'law' in terms of exchange rate movements, distance between markets, shipping costs and price discrimination.

We argue instead that the relationship between the prices of a commodity in any two markets is also highly dependent on the prevailing international and national policies. This is especially important when long samples of data are examined and policy interventions by governments are extensive and changing as in the case of coffee markets. What is important, therefore, is how we incorporate the effects of changing coffee market policies into our model of coffee prices.

We use the term 'policies' to include all measures to implement the international and domestic agreements such as administering the producer price and controlling the production and marketing of coffee as well as local taxes, export levies and subsidies, value added taxes, the setting of coffee grading standards, exchange rate and foreign exchange regulations and the provision of credit. Many of these policies change frequently and are difficult to document. However, they redistribute income either towards or away from producers and

5. See for example Fitter and Kaplinsky (2001), Ponte (2002), Oxfam (2002), Calfat and Flores (2002), Shepherd (2004), Talbot (2004) and Daviron and Ponte (2005).

6. For example see ActionAid (2008) and South Centre (2008).

7. The terminal price of coffee is the spot price of coffee as traded in international markets and the producer price of coffee is the cash price received at the 'gate' by producers. 
other participants in the coffee supply chain and may introduce a shift, or break, in the mean of the share of the terminal coffee price going to producers. ${ }^{8}$

The changes in policies at both the domestic and international levels and the eventual liberalisation of coffee markets raise a number of issues when modelling coffee prices. For example, consider the terminal and producer prices for Brazilian, Guatemalan and Indian Arabica coffee measured in US cents per pound. ${ }^{9}$ There are three striking features of the data. First, the difference, or gap, between the terminal and producer prices of coffee varies considerably over time in all three countries. This gap is an indirect measure of the costs of transferring coffee from the producer to the terminal markets. Between January 1973 and December 1989 the average transfer costs were around 85 (141 per cent of the average producer price), 45 (54 per cent), and 58 ( 72 per cent) US cents per pound of coffee for Brazil, Guatemala and India respectively. Since January 1990, following liberalisation, there has been a marked decline in these costs to around 18 (28 per cent), 32 (46 per cent) and 30 (42 per cent) US cents per pound of coffee respectively. It is unlikely that such large reductions in transfer costs can be explained by changes in freight, handling and related costs alone. It is more likely the reductions are due to changes in the economic rents received by intermediaries and governments in the transfer process arising from the greater degree of vertical integration in coffee markets. ${ }^{10}$

The variation in the gap between the terminal and producer coffee prices for each of these countries appears to provide prima facie evidence that the 'law of one price' does not hold. The 'law' suggests that the prices of two identical goods in two separate markets will differ in equilibrium by the cost of transferring the goods between the markets. Importantly this implies that the two prices will evolve together and that the gap between the two prices in equilibrium will be constant. This 'law' is predicated on an unchanging economic environment which in the case of coffee markets is difficult to sustain. Changes in coffee market policies at the domestic and international levels will alter the economic environment and may lead to discrete changes in the gap between the two prices. Consequently, the changes that we observe in the gap between the two coffee prices may be due to either a change in the economic environment (i.e. changes in policy) or because the 'law' does not hold. Therefore, to examine empirically the dynamics of coffee prices with a model that incorporates the 'law' we need to control for the effects of changes in coffee market policies.

8. For example, if the administered producer price of coffee is not changed in line with the terminal price of coffee it will lead to a change in the share of the terminal price received by producers.

9. Prices are in nominal terms unless stated otherwise. See Supplementary Appendix S2 for details of the data and S3 for a graph of the coffee price data.

10. See Mohan (2007). 
The second feature follows from the first. Large changes in transfer costs associated with changing government policies, regulations and market structure may cause structural breaks in the mean of the producers' share of the terminal price of coffee. The share is the ratio of the producer to the terminal price of coffee and is referred to in the paper as the coffee price ratio. These breaks are at times quite sudden and persistent as demonstrated in Figure 1 of the coffee price ratios for the three countries. ${ }^{11}$ Third, the nominal price of coffee received by producers at the beginning of the $21^{\text {st }}$ century is much the same as it was in the early 1970 s suggesting a large fall in real terms. This fall in the real price of coffee is demonstrated in Table 1.

All of these features lead us to argue that if the terminal and producer prices of coffee are closely related then any modelling of the two prices must take the structural breaks in the coffee price ratio into account. Otherwise estimating the model will result in biased and poor estimates that may lead to incorrect inferences. We therefore model the relationship between the terminal and producer prices of coffee in Brazil, Guatemala and India allowing for the breaks in the mean of the coffee price ratio. These three countries are chosen due to the variation in their coffee policies and market structures over time. We demonstrate that the modelling approach we adopt is successful in dealing with this variation.

We develop a two-step model of coffee prices. In the first step we employ the Bai and Perron (1998) (Bai-Perron) technique to identify multiple breaks in the mean of the natural logarithm of the coffee price ratio. In the second step we estimate a vector autoregressive error correction model (VAR-ECM) of coffee prices conditioned on the identified breaks. A major advantage of this approach is that if the law of one price holds then the estimated error correction term is equivalent to the log of the coffee price ratio and the structural breaks in the coffee price ratio identified in the first step are simultaneously the breaks in the mean of the error correction term. A further advantage of this approach is that we can examine directly the empirical relevance of the 'law of one price' after accounting for the influence of changing policies on coffee prices.

The next section sets out the standard approach to modelling coffee prices based on the 'law of one price' and explains the biases from not allowing for the breaks in the coffee price ratio. Section II reports the results of the estimated models allowing for these breaks. We find that once we account for the breaks in the coffee price ratio the 'law of one price' is strongly supported by the data. This allows us to show that the producers' share of the terminal price of coffee in equilibrium has increased in all three countries since liberalisation to around 0.85 in Brazil and India and 0.79 in Guatemala. Assuming that

11. In the empirical analysis that follows including estimating the breaks in the coffee price ratio, unit root tests and the estimation of the models, the variables are in natural logarithms. 
Figure 1. The Coffee Price Ratio
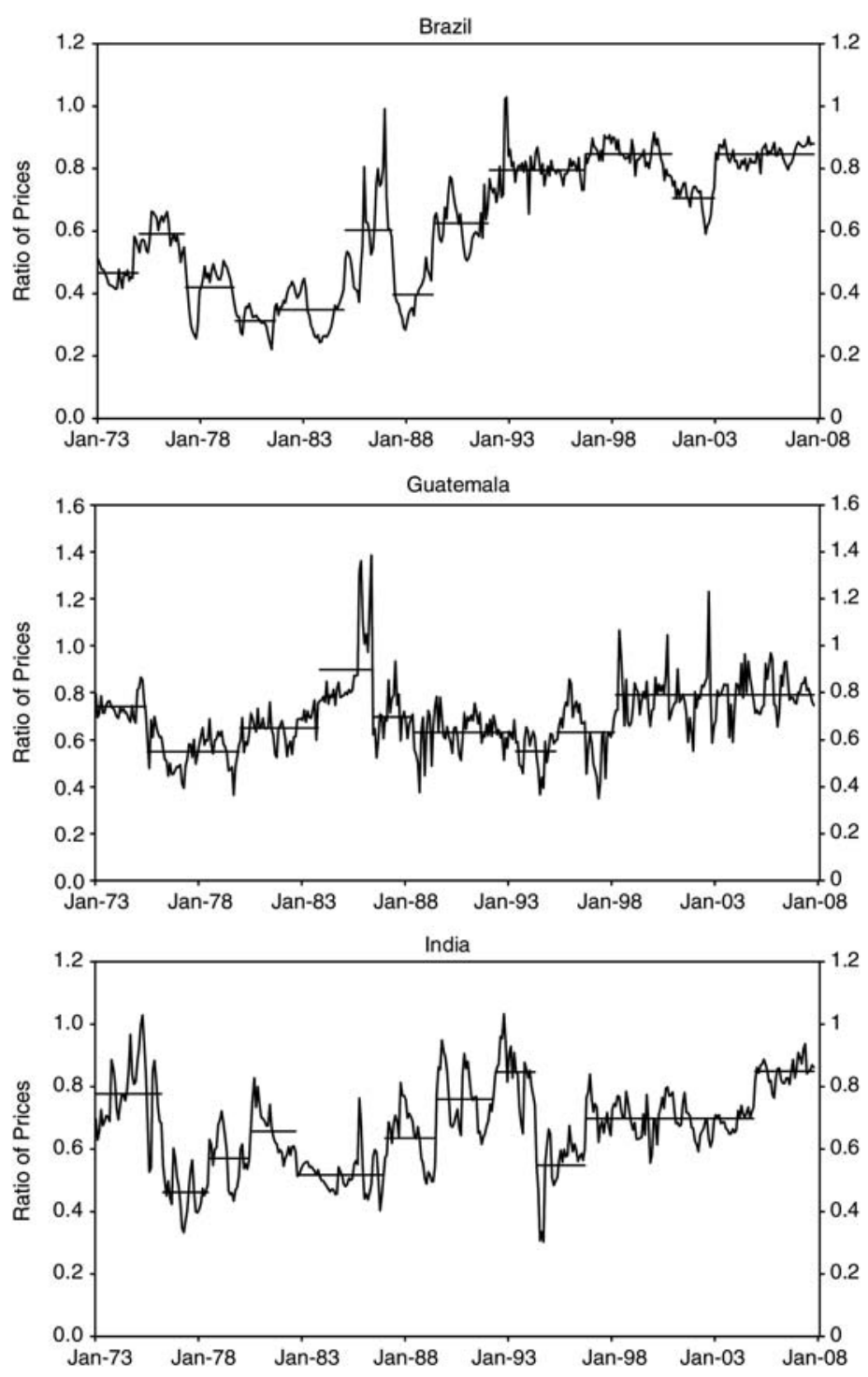

Note: Thick line is the coffee price ratio (not logged). The horizontal thin lines are the mean of the coffee price ratio for the 'regimes' estimated by the Bai-Perron technique as described in Supplementary Appendix S4.

liberalised markets led to these higher producer shares we demonstrate in Section III that the loss of revenue to producers from coffee market regulations and interventions over the years is substantial. Our analysis shows that producers have benefited since liberalisation from an increase in real prices, output and higher share in the terminal price of coffee. This indicates that calls for a 
Table 1. Nominal and Real Coffee Prices

\begin{tabular}{|c|c|c|c|c|c|c|}
\hline \multicolumn{7}{|c|}{ Brazil } \\
\hline & \multicolumn{3}{|c|}{ Nominal Values } & \multicolumn{3}{|c|}{ Real Value } \\
\hline & Producer Price & Terminal Price & Transfer Costs & Producer Price & Terminal Price & Transfer Costs \\
\hline 1973 & 31.02 & 69.20 & 38.19 & 1 & 1 & 1 \\
\hline 1990 & 55.58 & 82.97 & 29.39 & 0.5832 & 0.4048 & 0.2599 \\
\hline 2007 & 98.23 & 111.66 & 13.44 & 0.9273 & 0.4725 & 0.1030 \\
\hline \multicolumn{7}{|c|}{ Percentage Change } \\
\hline $1973-1990$ & $72.7(3.3)$ & $19.9(1.1)$ & $-23.0(-1.5)$ & $-41.7(-3.1)$ & $-59.5(-5.2)$ & $-74.0(-7.6)$ \\
\hline $1990-2007$ & $83.3(3.6)$ & $34.6(1.8)$ & $-54.3(-4.5)$ & $59.0(2.8)$ & $16.7(0.9)$ & $-60.7(-5.3)$ \\
\hline $1973-2007$ & $216.7(3.4)$ & $61.4(1.4)$ & $-64.8(-3.0)$ & $-7.3(-0.2)$ & $-52.8(-2.2)$ & $-89.7(-6.5)$ \\
\hline \multicolumn{7}{|c|}{ Guatemala } \\
\hline & \multicolumn{3}{|c|}{ Nominal Values } & \multicolumn{3}{|c|}{ Real Value } \\
\hline & Producer Price & Terminal Price & Transfer Costs & Producer Price & Terminal Price & Transfer Costs \\
\hline 1973 & 46.03 & 62.30 & 16.27 & 1 & 1 & 1 \\
\hline 1990 & 54.58 & 89.46 & 34.87 & 0.4004 & 0.4848 & 0.7235 \\
\hline 2007 & 98.09 & 123.55 & 25.46 & 0.6240 & 0.5807 & 0.4581 \\
\hline \multicolumn{7}{|c|}{ Percentage Change } \\
\hline $1973-1990$ & $18.6(1.0)$ & $43.6(2.2)$ & $114.3(4.6)$ & $-60.0(-5.2)$ & $-51.5(-4.2)$ & $-27.6(-1.9)$ \\
\hline $1990-2007$ & $79.7(3.5)$ & $38.1(1.9)$ & $-27.0(-1.8)$ & $55.9(2.6)$ & $19.8(1.1)$ & $-36.7(-2.7)$ \\
\hline $1973-2007$ & $113.1(2.3)$ & $98.3(2.0)$ & $56.5(1.3)$ & $-37.6(-1.4)$ & $-41.9(-1.6)$ & $-54.2(-2.3)$ \\
\hline
\end{tabular}




\begin{tabular}{|c|c|c|c|c|c|c|}
\hline & & & India & & & \\
\hline & & Nominal Values & & & Real Value & \\
\hline & Producer Price & Terminal Price & Transfer Costs & Producer Price & Terminal Price & Transfer Costs \\
\hline 1973 & 45.37 & 62.30 & 16.93 & 1 & 1 & 1 \\
\hline 1990 & 66.75 & 89.46 & 22.70 & 0.4968 & 0.4848 & 0.4527 \\
\hline 2007 & 108.34 & 123.55 & 15.21 & 0.6992 & 0.5807 & 0.2630 \\
\hline & & & Percentage C & & & \\
\hline $1973-1990$ & $47.1(2.3)$ & $43.6(2.2)$ & $34.1(1.7)$ & $-50.3(-4.0)$ & $-51.5(-4.2)$ & $-54.7(-4.6)$ \\
\hline $1990-2007$ & $62.3(2.9)$ & $38.1(1.9)$ & $-33.0(-2.3)$ & $40.8(2.0)$ & $19.8(1.1)$ & $-41.9(-3.1)$ \\
\hline $1973-2007$ & $138.8(2.6)$ & $98.3(2.0)$ & $-10.2(-0.3)$ & $-30.1(-1.0)$ & $-41.9(-1.6)$ & $-73.7(-3.9)$ \\
\hline Notes: Figures & ackets are the $\mathrm{c}$ & unded annualisec & centage change. & & Unit Values of Exports & US CPI \\
\hline Real values ar & lculated with ref & to the $\mathrm{UN}$ ind & unit values of & $1973-1990$ & $196.2(6.6)$ & $194.1(6.6)$ \\
\hline exports. Simila & sults are obtainec & e real price of $c$ & is measured in & $1990-2007$ & $15.3(0.8)$ & $58.7(2.8)$ \\
\hline terms of the & ed States consun & ice index (CPI). & hual values are & $1973-2007$ & $241.5(3.7)$ & $366.6(4.6)$ \\
\hline averages of th & thly values. $\mathrm{Nc}$ & 1 values are in & nts per pound. & & & \\
\hline Transfer cost & he difference bet & the terminal and & lucer price. The & & & \\
\hline of exports a & ted States C & & & & & \\
\hline
\end{tabular}


return to coffee market interventions of the kind that existed prior to liberalisation are not justified.

\section{Modelling Coffee Prices}

The standard approach to modelling coffee prices can be motivated with reference to the Enke (1951), Samuelson (1952), Takayama and Judge (1971) spatial models of prices and the 'law of one price'. ${ }^{12}$ These models argue that when two markets attain equilibrium the prices differ only by the costs of transferring the goods between the markets. The transfer costs include the shipping and storage costs associated with moving produce between markets along with the economic rents of intermediate agents in the supply chain. In this model, demand and supply shocks are fully transmitted between the two markets in equilibrium.

The standard approach incorporates Samuelson's (1957) spatial competitive market where prices of the same good in two markets diverge subject to the constraint that:

$$
-T C_{12} \leq P_{1}-P_{2} \leq T C_{21}
$$

where $P_{1}$ and $P_{2}$ are prices in markets one and two respectively and $T C_{12}$ are the costs of transferring the goods from market 1 to market 2 and $T C_{21}$ is the reverse. Samuelson points out that with positive transport costs both equalities cannot hold simultaneously and that if both inequalities hold then there is no trade between the two markets. However, if one inequality and one equality holds then there may be a uni-directional trade from the lower priced market to the higher priced market. In our case we assume the trade flow is from the producer to the terminal market for coffee such that arbitrage in a competitive market leads to:

$$
P_{T}=P_{P}+T C_{P T}
$$

where $P_{T}>P_{P}$ and $P_{T}$ and $P_{P}$ are the terminal and producer prices of coffee respectively and $T C_{P T}$ are the transfer costs associated with transferring coffee between the producer and terminal markets. The equilibrium in coffee prices between the terminal and producer markets can then be represented in these spatial models as:

$$
P_{P, t}=P_{T, t}^{*} U^{e}
$$

where $U^{e}$ is the constant ratio that coffee prices in the two markets attain in equilibrium and the ' $t$ ' subscript indicates the time period of the data. Note that even though it is assumed that the physical trade in coffee is uni-

12. The model can be thought of as 'spatial' in terms of the geographic locations of producer and terminal coffee markets. 
directional the causation between the two prices in equation (3) is conceptually bi-directional.

With $U^{e}<1$ in equation (3) we can identify transfer costs, $T C_{t}$, associated with the movement of coffee between the two markets such that $T C_{t}=P_{T, t}-P_{P, t}$ which are also measured in price per unit of coffee. In the short run the equilibrium relationship (3) need not apply due to the incomplete transfer of information between markets and other rigidities. For example, producer prices may not immediately respond to changes in the terminal price of coffee due to the fragmented nature of the supply chain and the need for all prices and costs in that chain to adjust. One might also assume that there are small 'menu costs' associated with adjusting costs and prices within the supply chain implying the producer price may diverge from its equilibrium level. However, in the long run we expect all prices and costs to respond to competitive pressures and the equilibrium relationship of equation (3) will hold if information is shared efficiently between markets and all agents make normal profits.

An assumption of this model that is not often highlighted in the literature is that the transfer costs in equilibrium are a fixed ratio of both the terminal and producer prices of coffee. For example, transfer costs as a ratio to, or share of, the terminal price of coffee in equilibrium is:

$$
\frac{T C_{t}}{P_{T, t}}=\frac{P_{T, t}-P_{P, t}}{P_{T, t}}=1-U^{e}
$$

Importantly, this implies that if the equilibrium in coffee prices is adequately described by this model, the statistical process of the transfer costs is the same as that of the two coffee prices in equilibrium. If this were not the case, when equilibrium coffee prices are attained in the two markets, transfer costs will not have returned to its equilibrium ratio in terms of the respective coffee prices. This implication is important for our modelling of coffee prices below.

The equilibrium relationship in equation (3) above has a straightforward time series interpretation in terms of a vector autoregressive-error correction model of coffee prices. Consider the following error correction representation of a two variable VAR of order $k$ :

$$
\Delta x_{t}=\delta+\alpha \beta^{\prime} x_{t-1}+\sum_{i=1}^{k-1} \Pi_{i} \Delta x_{t-i}+\varepsilon_{t}
$$

where, $x_{t}=\left(\begin{array}{c}p_{P} \\ p_{T}\end{array}\right)_{t}$, and $\alpha=\left(\begin{array}{cc}\alpha_{11} & \alpha_{12} \\ \alpha_{21} & \alpha_{22}\end{array}\right)$ is a matrix of equilibrium speed of adjustment coefficients, $\beta$ is a matrix containing the equilibrium vectors $\left(\begin{array}{ll}1 & \beta_{12} \\ 1 & \beta_{22}\end{array}\right), \Pi_{i}$ is a matrix of short-run coefficients, lower case variables are in 
natural logarithms and $\Delta$ represents the change in the variable such that $\Delta x_{t}=x_{t}-x_{t-1}$.

The error correction representation argues that the producer and terminal prices of coffee move together and coffee prices converge on the equilibrium relationship. Changes in coffee prices depend on the deviation from the equilibrium relationship and the speed of adjustment (i.e. the error correction mechanism) along with lagged changes in the prices of coffee.

The standard approach to estimating the VAR-ECM of coffee prices proceeds within a cointegration framework. ${ }^{13}$ If coffee prices, $p_{P}$ and $p_{T}$ are integrated processes and cointegrate, the matrices $\alpha$ and $\beta$ must be of reduced rank and in our case would be equal to one. No cointegration implies a rank of zero.

While it is common to model price data as integrated processes, in reality prices cannot be 'truly' integrated as they have a lower boundary of zero. It is more likely, therefore, that prices are trend stationary processes with breaks and it is these breaks that make the data appear integrated. ${ }^{14}$ For coffee prices the trend is very small or non-existent and the natural logarithm of coffee prices and the coffee price ratio appear to be stationary processes over the past thirty four years. This can be verified by the ADF and KPSS univariate unit root tests reported in columns 1 and 2 of Table 2 . Note however that even though the trend is difficult to identify in the coffee price data the ADF test indicates that the coffee price ratio is a trend stationary process for all three countries. Consequently, the standard cointegration approach to modelling coffee prices is not appropriate and the modelling framework is a VAR-ECM of stationary price variables with possible breaks in the error correction term.

The equilibrium relationship in equation (5) can be written:

$$
\beta^{\prime} x_{t}=p_{P, t}+\beta p_{T, t}=z_{t}
$$

where $z_{t}$ is a stationary process. Furthermore, if $\beta=-1$ then the equilibrium vector can be interpreted as the equilibrium relationship of equation (3) where:

$$
p_{P, t}-p_{T, t}=u_{t}
$$

and the error correction mechanism is now equivalent to the natural logarithm of the coffee price ratio, $u_{t}$.

Note that when $\beta=-1$, the standard model in equations (3) and (6) displays long-run homogeneity which is equivalent to accepting the 'law of one price'. This means that a 1 per cent increase in one coffee price leads to a 1 per cent increase in the other price in equilibrium so that transfer costs as a proportion of either the terminal or the producer price are unchanged. This also

13. For example see Rapsomanikas et al. (2004), Fortenbery and Zapta (2004), Krivonos (2004) and Alizadeh and Nomikos (2005).

14. See Perron (1989). 
TABle 2. Univariate Unit Root Tests

\begin{tabular}{|c|c|c|c|c|}
\hline \multirow{2}{*}{$\begin{array}{l}\text { Series } \\
\text { Brazil }\end{array}$} & \multicolumn{2}{|c|}{ Original Data } & \multicolumn{2}{|c|}{ De-meaned Data } \\
\hline & $\mathrm{ADF}$ & KPSS & $\mathrm{ADF}$ & KPSS \\
\hline Ln Producer Price & $\begin{array}{c}-3.48 \\
{[0.0089]}\end{array}$ & $0.0688 * 10 \%$ & $\begin{array}{c}-4.33 \\
{[0.0005]}\end{array}$ & $0.0437^{10 \%}$ \\
\hline Ln Terminal Price & $\begin{array}{c}-2.91 \\
{[0.0454]}\end{array}$ & $0.1195 * 5 \%$ & $\begin{array}{c}-4.02 \\
{[0.0014]}\end{array}$ & $0.0427^{10 \%}$ \\
\hline Ln Ratio of Coffee Prices & $\begin{array}{l}-3.33^{*} \text { \# } \\
{[0.0634]}\end{array}$ & $0.1975 * 1 \%$ & $\begin{array}{c}-7.57^{\#} \\
{[0.0000]}\end{array}$ & $0.0197^{10 \%}$ \\
\hline \multicolumn{5}{|l|}{ Guatemala } \\
\hline Ln Producer Price & $\begin{array}{c}-3.01 \\
{[0.0350]}\end{array}$ & $0.1658^{10 \%}$ & $\begin{array}{c}-4.33 \\
{[0.0005]}\end{array}$ & $0.0468^{10 \%}$ \\
\hline Ln Terminal Price & $\begin{array}{c}-2.91 \\
{[0.0454]}\end{array}$ & $0.1252 * 5 \%$ & $\begin{array}{c}-4.02 \\
{[0.0014]}\end{array}$ & $0.0434^{10 \%}$ \\
\hline Ln Ratio of Coffee Prices & $\begin{array}{c}-6.10^{*} \\
{[0.0000]}\end{array}$ & $0.1363 * 5 \%$ & $\begin{array}{c}-11.61 \\
{[0.0000]}\end{array}$ & $0.0236^{10 \%}$ \\
\hline \multicolumn{5}{|l|}{ India } \\
\hline Ln Producer Price & $\begin{array}{c}-3.00 \\
{[0.0361]}\end{array}$ & $0.1081^{10 \%}$ & $\begin{array}{c}-3.84^{\#} \\
{[0.0027]}\end{array}$ & $0.1252^{10 \%}$ \\
\hline Ln Terminal Price & $\begin{array}{c}-2.91 \\
{[0.0454]}\end{array}$ & $0.1252 * 5 \%$ & $\begin{array}{c}-4.62 \\
{[0.0001]}\end{array}$ & $0.1232^{10 \%}$ \\
\hline Ln Ratio of Coffee Prices & $\begin{array}{c}-5.71^{*} \\
{[0.0000]}\end{array}$ & $0.1154 * 10 \%$ & $\begin{array}{c}-10.00 \\
{[0.0000]}\end{array}$ & $0.0203^{10 \%}$ \\
\hline
\end{tabular}

Notes: The data are in natural logarithms as indicated by 'Ln'. 'Ln Ratio of Coffee Prices', $u_{t}$, is measured as $p_{P, t}-p_{T, t}$. ADF is the augmented Dickey-Fuller $t$-statistics that assumes a null hypothesis of a unit root in the data. Associated probability values are shown as [ ]. ADF 5 per cent critical values with a constant is -2.87 and with a trend and constant -3.43 . A lag length of one in the ADF test was chosen on the basis of SIC in all cases except when zero as indicated by \#.

KPSS is the Kwiatkowski-Phillips-Schmidt-Shin LM test statistic that assumes a null hypothesis that the data are stationary. KPSS 1,5 and 10 per cent critical values with a constant are 0.7390 , 0.4630 and 0.3470 respectively and with a trend and constant $0.2160,0.1460$ and 0.1190 . The percentage shown with the KPSS test statistic is the significance level that the null hypothesis is accepted at.

De-meaned data adjusts the original data for the shifts in mean as identified by the Bai-Perron technique for each country (see Supplementary Appendix S4). " indicates a significant trend in the unit root test. In all other cases the trend is insignificant and excluded prior to inference.

implies that transfer costs have increased by 1 per cent in the long run. With trending price and cost variables we need $\beta=-1$ so that a persistent change in the level of coffee prices does not lead to a persistent change in the gap between the two prices in equation (5). In other words, $\beta=-1$ implies that a change in the level of prices leaves the coffee price ratio unchanged in equilibrium and transfer costs increase in line with prices.

Two important assumptions concerning the equilibrium relationship (7) and the VAR-ECM analysis are that the coffee price ratio, $u_{t}$, converges on a constant value, $u^{e}$, in equilibrium and that $u_{t}$ is a stationary process with a constant mean equal to $u^{e}$. Looking closely at Figure 1 we can however see discrete shifts in the mean of the coffee price ratio. Thus, the finding of 
stationarity of the coffee price ratio notwithstanding, it is worth investigating whether breaks are present in this series. These visual shifts in the ratio can be tested formally by applying the Bai-Perron technique, which allows for breaks in otherwise stationary processes, for identifying multiple structural breaks in the mean of the coffee price ratio, $u_{t} \cdot{ }^{15} \mathrm{~A}$ justification for the likely presence of such breaks is provided in the paragraph below. The Bai-Perron technique identifies 11,8 and 10 discrete shifts in the mean of the coffee price ratio for Brazil, Guatemala and India and the shifting mean coffee price ratio are shown in Figure 1 by horizontal thin lines. ${ }^{16}$

Our reasons for proceeding with our analysis with the maintained assumption that the identified breaks in the coffee price ratio are valid are two-fold. First, incorporating the breaks improves the estimated model's description of the coffee price data considerably. Second, the converse assumption, namely that the coffee price ratio is stationary with a constant mean, is difficult to sustain. For example, if the converse were true then all the changes in coffee market policies over the past thirty five years have had no persistent impact on the share of the terminal price of coffee that goes to producers. More importantly, the vociferous arguments surrounding the merits of either regulating coffee markets or de-regulating coffee markets are largely irrelevant as neither policy would have had any persistent impact on the coffee price ratio. Therefore, both these implications of assuming a stationary process with constant mean are hard to defend empirically and at a policy level.

The number of breaks that we find in the mean of the coffee price ratio may seem large relative to that usually reported in the applied structural breaks literature. However, this result is consistent with producer prices being largely administered during the first seventeen years of the data and the coffee market being de-regulated in irregular steps over the next seventeen years. Consequently, over the entire thirty four years examined in the empirical analysis, the coffee price ratio can be characterised as being subject to discrete and irregular shocks. Finding around ten breaks over a thirty-four year period implies that a break occurred only once every thirty six months on average which is broadly consistent with the rate of structural change and interventions in coffee markets over the period studied. We return to the issue of the validity of the identified structural breaks in Section II following the estimation of the models below.

It appears, therefore, that the two important assumptions mentioned above, namely that the coffee price ratio is a stationary process with a constant mean and converges on a constant value in equilibrium, are not valid. This suggests the mean of the coffee price ratio may be discretely time-varying and the

15. See Supplementary Appendix S4 for details of the Bai-Perron estimates of the structural breaks.

16. If the breaks in the coffee price ratio are valid this implies Type 1 and Type 2 errors in the ADF and KPSS tests respectively in Table 2. 
equilibrium coffee price ratio could be written in a more general form that contains a trend, $t$, and $n$ shift dummies $D_{i}$ :

$$
p_{P, t}+\beta_{1} p_{T, t}+\beta_{2} t+\sum_{i=1}^{n} \delta_{i} D_{i}=\omega_{t}
$$

The inclusion of the trend is intended to capture a systematic divergence between the terminal and producer prices in equilibrium. This would occur if transfer costs evolved differently to coffee prices over the longer term. Transfer costs may be driven by factors such as the wage rate, productivity, shipping rates, insurance, technological advances incorporated in the supply chain, real interest rates, energy costs and inventory control which may not affect to the same extent the prices of homogeneous agricultural products like coffee. The shift dummies represent discrete structural breaks in the coffee price ratio in response to changing domestic and international coffee market policies.

If estimation of the model proceeds assuming that the mean ratio of coffee prices is time invariant as implicitly (or explicitly) assumed in the standard literature then the estimates of the equilibrium coefficients, $\beta$, and the adjustment coefficients in equation (5) will be poor and biased if the coffee price ratio, $u_{t}$, is in fact non-stationary (i.e as described by (8) above). The direction of the bias in $\beta$ depends on whether the coffee price ratio is on average increasing or decreasing over the period. The adjustment coefficients will be biased downwards if the shifts in the mean coffee price ratio are not accounted for. From the perspective of the estimated model it will appear that the coffee price ratio is taking a long time (i.e. the speed of adjustment is low) to return to the equilibrium coffee price ratio following a change in the mean coffee price ratio in the data. Consequently, how we model the coffee price ratio may affect our estimates in important ways.

\section{Estimating a VAR-ECM of Coffee Prices}

The models are estimated in natural logarithms using the monthly average International Coffee Organization (ICO) Indicator Price for Arabica coffee ('Brazilian Natural' Arabica for Brazil and 'Other Mild' Arabica for Guatemala and India) as a measure of terminal prices and the monthly average producer price for Arabica coffee in Brazil, Guatemala and India for the period January 1973 to October 2007. All price data are in nominal terms and measure a monthly average price in US cents per pound. Further details concerning the data are provided in Supplementary Appendix S2.

\section{Modelling coffee prices without structural breaks}

Estimates of the standard VAR-ECM model that do not account for the structural breaks in the mean of the coffee price ratio are reported in Table 3. While there is some variation in the estimates there is a strong pattern in the results. A trend is significant for all three countries suggesting that there has been a 
BRAZIL

\begin{tabular}{|c|c|c|c|c|c|}
\hline \multirow[b]{3}{*}{ Unrestricted } & \multicolumn{3}{|c|}{ Equilibrium Coefficients } & \multicolumn{2}{|c|}{ Adjustment Coefficients } \\
\hline & $p_{P}$ & $p_{T}$ & Trend & $\Delta p_{P}$ & $\Delta p_{T}$ \\
\hline & 1.0000 & $-0.7010(-4.7)$ & $-0.1828(-3.1)$ & $-0.0630(-3.0)$ & $-0.0044(-0.3)$ \\
\hline Restricted & 1.0000 & -1.0000 & $-0.0048(-4.3)$ & $-0.0351(-1.6)$ & $0.0199(1.2)$ \\
\hline
\end{tabular}

$p_{T}=0.0883$, Trend $=0.0830$. Exogeneity: $P_{P}=0.0494, p_{T}=0.8594$

Equilibrium Coefficients

\begin{tabular}{|c|c|c|c|c|c|}
\hline & & Equilibrium Coe & EMALA & Adjust & ents \\
\hline & $p_{P}$ & $p_{T}$ & Trend & $\Delta p_{P}$ & $\Delta p_{T}$ \\
\hline Unrestricted & 1.0000 & $-0.9571(-13.9)$ & $-0.0495(-2.2)$ & $-0.2022(-6.0)$ & $0.0218(1.0)$ \\
\hline Restricted & 1.0000 & -1.0000 & $-0.0528(-2.3)$ & $-0.1935(-5.9)$ & $0.0268(1.3)$ \\
\hline
\end{tabular}

$p_{T}=0.0000$, Trend $=0.0381$. Exogeneity: $p_{P}=0.0000, p_{T}=0.3724$

\section{INDIA}

Equilibrium Coefficients

\begin{tabular}{ccc}
\multicolumn{3}{c}{ Equilibrium Coefficients } \\
\hline$p_{P}$ & $p_{T}$ & Trend \\
1.0000 & $-0.7783(-12.0)$ & $-0.0514(-2.4)$ \\
1.0000 & -1.0000 & $-0.3474(-2.4)$
\end{tabular}

Adjustment Coefficients

$\begin{array}{cc}\Delta p_{P} & \Delta p_{T} \\ -0.0913(-4.0) & 0.0864(3.7) \\ -0.0508(-2.8) & 0.0788(4.3)\end{array}$

$\begin{array}{lllll}\text { Unrestricted } & 1.0000 & -0.0514(-2.4) & -0.0913(-4.0) & -0.0508(-2.8) \\ \text { Restricted } & 1.0000 & -1.0000 & -0.3474(-2.4) & 0.0788(4.3)\end{array}$

$\mathrm{TLRR}=0.0316, \mathrm{TT}=0.0364, \mathrm{LM}_{1}=0.3603, \mathrm{LM}_{2}=0.5283$. Normality $=0.0000$. Stationarity: $p_{P}=0.0000, p_{T}=0.0000$. Exclusion: $p_{P}=0.0000$,

$p_{T}=0.0000$, Trend $=0.0226$. Exogeneity: $p_{P}=0.0003, p_{T}=0.0009$.

Notes: Reported as ( ) are t-statistics. The trend is multiplied by 100 . The models and statistics are estimated with two lags of the core variables and an effective sample of 416 monthly observations for the period January 1973 to October 2007 . The number of lags was chosen by a likelihood ratio test for lag reduction. TLRR and TT are the finite sample Bartlett corrected probability values of the test of the equilibrium restriction that $\beta=-1$ and the likelihood ratio exclusion test of the estimated trend respectively. $\mathrm{LM}_{1}$ and $\mathrm{LM}_{2}$ are the probability values of the Lagrange Multiplier tests of no serial correlation in the errors of lags 1 and 2 respectively. Normality is the probability value of the Doornik-Hansen test for normal errors. Stationarity, Exclusion and Exogeneity are the probability values of the likelihood ratio tests that $p_{P}$ and $p_{T}$ (and trend if applicable) are stationary, can be excluded from the equilibrium relationship and/or weakly exogenous respectively. Estimated with CATS 2.0. 
trend increase in the producer price of coffee relative to terminal prices over the period examined. The estimated models for Brazil and India appear to be relatively poor representations of the dynamics of the coffee prices with the adjustment coefficients largely insignificant for Brazil and small for India. The results for Guatemala are the best behaved where we accept the long-run homogeneity restriction that $\beta=-1$ with the adjustment coefficients moderately large and significant. Consequently, with the possible exception of Guatemala, we might conclude that a VAR-ECM is a relatively poor representation of the dynamics of coffee prices. The inconclusive nature of these results is consistent with the view that structural breaks are an important feature of the price series being modelled and therefore need to be taken into account in order to develop a more accurate description of the system generating coffee prices.

\section{Modelling coffee prices with structural breaks}

Breaks in the mean of the coffee price ratio are due to breaks in the component coffee price series. However, simultaneous breaks of equal magnitude will not affect the ratio. That is, the coffee price ratio will break if either the breaks in the price series occur at different points of time or when occurring simultaneously they are of different magnitudes. While there may be numerous events that impact simultaneously on both price series the discussion above focuses on changes to policy and market structure that impact on the coffee price ratio. Therefore, our preferred approach is to identify breaks in the mean of the coffee price ratio directly by applying the Bai and Perron (1998) algorithm. The identified breaks are those shown in Figure 1 and reported in Supplementary Appendix S4. Once we allow for these breaks in the coffee price ratio the univariate unit root tests reported in columns 3 and 4 of Table 2 lead to the unambiguous conclusion that the natural logarithm of the prices of coffee and their ratio are stationary.

Estimates of the VAR-ECM incorporating the breaks leads to the results reported in Table 4. The breaks are introduced as level shifts in the equilibrium relationship which account for the level shifts in the mean coffee price ratio evident in Figure 1. The inclusion of the shift dummies now leads to the rejection of the trend in the equilibrium relationship at the 5 per cent level for all three countries. This implies the shift dummies dominate the trend as a proxy for the shifts in the equilibrium coffee price ratio over the period. ${ }^{17}$ The shift dummies are highly significant which reinforces our conclusion that the Bai-Perron identified breaks are valid. The restriction that $\beta=-1$ can now be easily accepted for all three countries at the 5 per cent level implying we

17. Over the full sample the mean coffee price ratio increases and this results in a positive estimated trend in the standard model (see Figure 1 and Table 3). However, the structural breaks in Model 2 reported in Table 4 represent the evolution of the mean coffee price ratio better, resulting in the trend becoming insignificant. 
Table 4. VAR Error Correction Model of Coffee Prices: Model 2-Bai-Perron Break Adjusted

\section{BRAZIL}

\begin{tabular}{lccccc}
\hline & \multicolumn{2}{c}{ Equilibrium Coefficients } & & \multicolumn{2}{c}{ Adjustment Coefficients } \\
\cline { 2 - 3 } \cline { 5 - 6 } & $p_{P}$ & $p_{T}$ & & $\Delta p_{P}$ & $\Delta p_{T}$ \\
Unrestricted & 1.0000 & $-0.9058(-17.2)$ & & $-0.2652(-6.7)$ & $-0.0338(-1.1)$ \\
Restricted & 1.0000 & -1.0000 & & $-0.2420(-5.9)$ & $-0.0036(-0.1)$
\end{tabular}

TLRR $=0.2085, \mathrm{LM}_{1}=0.5148, \mathrm{LM}_{2}=0.0577$. Normality $=0.0000$. Stationarity: $p_{P}=0.0000$, $p_{T}=0.0000$. Exclusion: $p_{P}=0.0000, p_{T}=0.0000$. Exogeneity: $p_{P}=0.0000, p_{T}=0.3981$.

Dummies: December 1974, -0.2449 (-2.8); March 1977, 0.3939 (4.8); August 1979, 0.2806

(3.3); August 1981, -0.1225 (-1.5); December 1984, -0.5702 (-7.6); April 1987, 0.4842

(5.7); April 1989, -0.5049 ( -6.1 ); December 1991, -0.2544 (-3.8); August 1996, -0.0645

(-1.1); November 2000, 0.1965 (2.6); and December 2002, -0.2014 (-2.8).

\section{GUATEMALA}

\begin{tabular}{lccccc}
\hline & \multicolumn{2}{c}{ Equilibrium Coefficients } & & \multicolumn{2}{c}{ Adjustment Coefficients } \\
\cline { 2 - 3 } \cline { 5 - 6 } & $p_{P}$ & $p_{T}$ & & $\Delta p_{P}$ & $\Delta p_{T}$ \\
Unrestricted & 1.0000 & $-0.9189(-23.8)$ & & $-0.4547(-10.2)$ & $-0.0578(-1.9)$ \\
Restricted & 1.0000 & -1.0000 & & $-0.4117(-9.4)$ & $0.0852(2.9)$
\end{tabular}

TLRR $=0.1309, \mathrm{LM}_{1}=0.0001, \mathrm{LM}_{2}=0.6317$. Normality $=0.0000$. Stationarity: $p_{P}=0.0000$, $p_{T}=0.0000$. Exclusion: $p_{P}=0.0000, p_{T}=0.0000$. Exogeneity: $p_{P}=0.0000, p_{T}=0.1319$.

Dummies: June 1975, 0.2924 (5.4); December 1979, - 0.1562 (-3.3); October 1983, - 0.3316 (-6.1); May 1986, 0.3101 (4.8); May 1988, 0.0607 (1.1); April 1993, 0.1043 (1.8); April 1995, -0.1062 (-1.7); and February 1998, $-0.1693(-2.8)$.

\section{INDIA}

\begin{tabular}{lccccc}
\hline & \multicolumn{2}{c}{ Equilibrium Coefficients } & & \multicolumn{2}{c}{ Adjustment Coefficients } \\
\cline { 2 - 3 } \cline { 5 - 5 } & $p_{P}$ & $p_{T}$ & & $\Delta p_{P}$ & $\Delta p_{T}$ \\
Unrestricted & 1.0000 & $-1.0391(-24.1)$ & & $-0.1699(-5.8)$ & $0.2250(7.8)$ \\
Restricted & 1.0000 & -1.0000 & & $-0.1813(-6.0)$ & $0.2243(7.5)$ \\
& & & & \\
\hline
\end{tabular}

TLRR $=0.4704, \mathrm{LM}_{1}=0.0083, \mathrm{LM}_{2}=0.0777$. Normality $=0.0000$. Normality $=0.0000$. Stationarity: $p_{P}=0.0000, p_{T}=0.0000$. Exclusion: $p_{P}=0.0000, p_{T}=0.0000$. Exogeneity: $p_{P}=0.0000, p_{T}=0.0000$.

Dummies: March 1976, 0.5463 (10.5); June 1978, - 0.2231 (-3.9); June 1980, -0.1491 (-2.6); September 1982, 0.2442 (5.0); December 1986, - 0.2019 (-4.3); June 1989, -0.1842 (-3.6); April 1992, - 0.1102 (-2.0); April 1994, 0.4594 (8.1); September 1996, -0.2669 $(-6.2)$; and November 2004, $-0.2021(-5.1)$.

Notes: The shift dummies are those estimated in the restricted model. For further details see the notes to Table 3. 
simultaneously accept the 'law of one price' in relation to terminal and producer coffee prices. The error correction mechanisms are also strongly significant with large adjustment coefficients.

Therefore our results for the VAR-ECM with structural breaks are in accordance with the theoretical spatial model of prices. For example, the terminal and producer prices of coffee move very closely together as demonstrated by accepting the restriction that $\beta=-1$ and the existence of a powerful error correction mechanism in all three countries. Consequently, these results strongly favour the 'law of one price' once we adjust for the breaks in the mean of the coffee price ratio which we characterise as due to changing coffee market policies. The large adjustment coefficients reported in Table 4 imply that deviations from the equilibrium coffee price ratio are relatively small and transitory. Following a shock to the coffee price ratio, half of the adjustment to equilibrium occurs in around $2 \frac{1}{2}$ months for Brazil and 1 month for Guatemala and India. ${ }^{18}$ This can be seen in Figure 1 where the estimated equilibrium coffee price ratios are equivalent to the horizontal thin lines and deviations in, $u_{t}$, from the equilibrium ratio are mostly small and short lived.

Finally, it appears that modelling the discrete shifts in the coffee price ratio as structural breaks plays an important role in explaining the behaviour of coffee prices and the associated changing shares in the terminal prices going to producers. Extending the standard analysis to include the breaks improves our understanding of the behaviour of coffee prices significantly.

\section{Are the identified structural breaks valid?}

There are two ways to approach this question. The first is to identify particular events in the regulation of coffee markets that coincide roughly with the breaks in the coffee price ratio used in the empirical analysis. To this end Supplementary Appendix S1 provides a brief description of the regulations in the coffee markets of each of the three countries and relates the changing regulations with the breaks in the coffee price ratio reported in Supplementary Appendix S4. Of the twenty nine breaks identified in the data of the three countries by the Bai-Perron technique, twenty roughly coincide with historical events described in Supplementary Appendix S1.

The second approach focuses on the empirical results themselves and asks are the results robust to the number of breaks? In particular, is the large number of identified breaks causing the high speed of adjustment back to the equilibrium coffee price ratio and the acceptance of the law of one price? To examine whether our results are robust to the number of breaks we repeat the analysis by imposing the number of breaks to be half those identified in the models reported in Table 4 and to allow the Bai-Perron technique to choose

18. The adjustment speeds are calculated from simulations based on the estimates in Table 4 . 
the breaks optimally subject to this constraint. ${ }^{19}$ The estimates imposing half the number of breaks are found to be very similar qualitatively and statistically to those reported in Table 4 that incorporate the full number of breaks. ${ }^{20}$ For example, for all three countries: (i) the appropriate modelling framework is a VAR-ECM of stationary price variables with possible breaks in the error correction term; (ii) the trend remains insignificant; (iii) the long-run restriction of $\beta=-1$ can be accepted suggesting the law of one price continues to hold; (iv) the adjustment coefficients are slightly smaller but similar in magnitude and significance to those reported in the 'full' model reported in Table 4; (v) the shift dummies are highly significant; and (vi) the residuals are largely free of serial correlation as in the full model.

Therefore our estimated model is robust to halving the number of breaks. Consequently, if we reject the number of breaks that we find using statistical tests and instead impose a smaller number of breaks so as to conform with our prior views of the data then our general empirical results along with the associated policy conclusions and economic implications are largely unaffected.

\section{The Loss in Revenue to Producers from Coffee Market Regulation}

The equilibrium coffee price ratio is particularly useful for examining the impact of government policies and changing market structures on the coffee market as it abstracts from short-run variations and shocks to this ratio. Following the liberalisation of coffee markets the equilibrium coffee price ratio in levels has increased to around 0.85 for Brazil and India and 0.79 for Guatemala in the most recent period. Given that both the producer and terminal prices of coffee are largely market determined in the most recent period following liberalisation we might infer the coffee price ratios are their un-regulated market values. Furthermore, the empirical evidence presented in Section II suggests the 'law of one price' is strongly supported by the data. Consequently, as the terminal price of coffee has been largely market determined over the entire period we can calculate the counter-factual unregulated producer price of coffee by multiplying the terminal price of coffee in each period by the un-regulated market value for the coffee price ratio in 2007. This allows us to estimate the loss of revenue to producers due to regulation by examining the extent to which the actual producer price of coffee deviates from its counterfactual unregulated value.

The thin line in Figure 2 is the nominal loss in revenue to producers due to the regulation of coffee markets calculated as $Q_{t} \bullet P_{T, t} \bullet\left[U_{2007}^{e}-U_{t}^{e}\right]$ where $Q_{t}$ is the production of coffee and $U_{2007}^{e}$ and $U_{t}^{e}$ are the equilibrium coffee

19. The 'half-breaks' models imposes 6,4 and 5 breaks for Brazil, Guatemala and India respectively.

20. The results are available in Supplementary Appendix S5. 
Figure 2. The Nominal and Real Losses of Coffee Producers
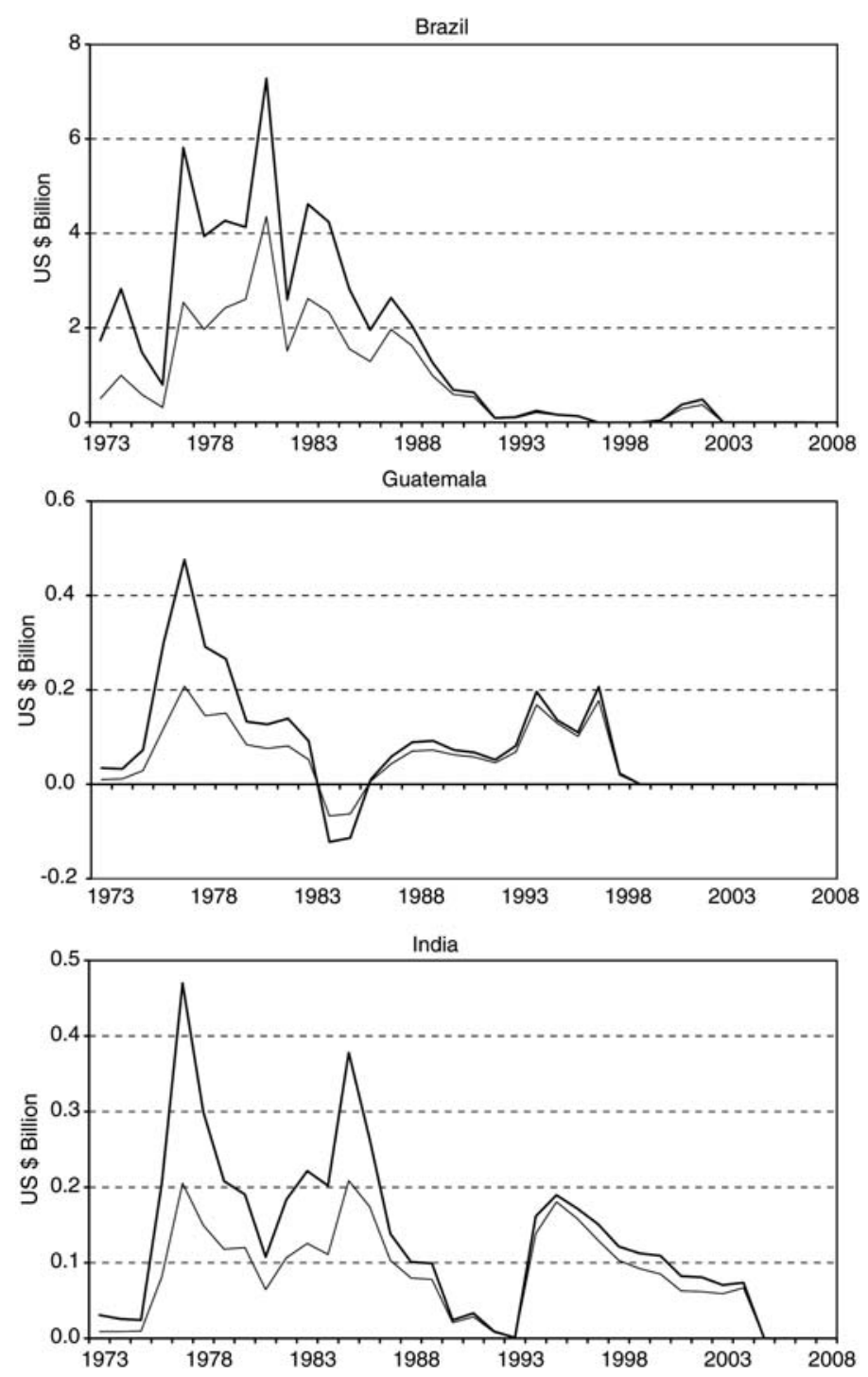

Note: The thin and thick lines are the nominal and real values (in 2007 prices) of the loss to producers. Real values are in terms of the UN index of unit values of exports.

price ratios in 2007 and in each year for each country respectively. This calculation assumes that production and the terminal price of coffee are independent of the market based coffee price ratio. Note that the law of one price means that $U^{e}$ is 'unit free' and a real number. This allows the unit of the loss to producers to be measured in US cents. The thick line in Figure 2 shows the real loss to producers measured in 2007 prices. 
We observe that producers suffered from a loss of revenue in all three countries during the 1970s and early 1980s. In 2007 prices, the real losses to producers peak at around US\$7 billion in the early 1980s for Brazil and around US\$0.45 billion for Guatemala and India in the mid-1970s. The losses trail off to negligible levels in the most recent periods following liberalisation in all three countries indicating that market interventions over the years have not been in the overall interest of producers. Note that these measures of loss are in respect to the producers alone and not necessarily to the country as a whole. The loss, or a part of the loss, may simply represent a transfer from the producer to either the government or intermediaries in the transfer process.

\section{Are Coffee Producers Better Off Due to Liberalisation?}

To answer this question we consider the impact that liberalisation has had on the revenue and input costs of producers. The impact on revenues can be thought of in terms of three interrelated issues. First, what has happened to the producer price of coffee? Second, what has happened to the quantity of coffee produced? And third, what has happened to the share of the terminal price of coffee that goes to the producer?

The common expectation from coffee market interventions was that they would result in an increase in the terminal and producer prices of coffee. If this were the case then the producer price of coffee should have fared better during the period of regulation than after liberalisation. This is not supported by Table 1. In the seventeen years prior to liberalisation, producer coffee price inflation is only half that of the 'world' inflation rate of 6.6 per cent as measured by the UN index of unit values of exports or the United States CPI. Producer prices increased by 3.3, 1.0 and 2.3 per cent per annum in Brazil, Guatemala and India but in real terms they fell over the period prior to liberalisation by 42, 60 and 50 per cent respectively.

In contrast, during the period 1990 to 2007 when coffee markets witnessed the phase of liberalisation, producer prices increased by 3.6, 3.5, and 2.9 per cent per annum in Brazil, Guatemala and India compared with 'world' inflation of less than 1 per cent per annum as measured by the UN index of unit values of exports. This means that the producer price of coffee increased by around 60,55 and 40 per cent in real terms after liberalisation. ${ }^{21}$ Coffee prices therefore did not match the growth in 'world' prices during the years of coffee market regulation up to 1990 but increased by more than 'world' prices after the liberalisation of coffee markets.

The data also shows there has been a large increase in coffee production following liberalisation in all three countries. Average coffee production in the

21. In the period 1990 to 2007 United States CPI deviates from the UN index of unit values of exports (see Table 1). However, if we use United States CPI as a measure of world inflation we find that producer prices still increase in real terms by around 15, 13 and 2 per cent respectively. 
seventeen years after 1990 is $1.3,1.3$ and 1.8 times the coffee production in the seventeen years prior to 1990 in Brazil, Guatemala and India respectively (ICO, 2007). There may be many reasons for this increase in production and we cannot say that the increase is solely due to liberalisation. But to the extent that liberalisation caused an increase in producer prices we can expect its effect on production was beneficial. We can also expect some increase in production because of the removal of restrictions that were imposed on the production of coffee prior to liberalisation. Akiyama (2001) argues that the removal of constraints of the international quota system meant that exports increased along with production. In addition, the liberalisation meant that higher quality coffee is no longer mixed with lower grades prior to export and the opportunity to export and obtain a premium on higher quality coffee has expanded. There was therefore an added incentive after liberalisation for producers to supply better quality coffee, which in turn has helped the growth in the consumption of coffee worldwide. In any case, as far as producers are concerned they have gained both in terms of prices and production following liberalisation. The empirical analysis above also demonstrates that the equilibrium coffee price ratio has increased systematically since liberalisation of coffee markets in all three countries. This increase means that liberalisation has improved the returns to producers by reducing the net transfer costs throughout the coffee supply chain.

Therefore, the answer to the question of whether producers are better off in terms of the revenue that they receive since liberalisation appears to be unambiguously yes. Producers have benefited from a higher real price of coffee, higher coffee production and a higher share of the terminal price of coffee.

The impact of liberalisation on the input costs of producers is obscured by the lack of data at the producer level. ${ }^{22}$ However, there are studies that estimate the relative input shares for the production of coffee. For example, ICO (1996/97) reports that the annual cost shares for small holder Arabica production in India are 54, 26, 7 and 14 per cent for labour, materials (fertiliser, pesticide, bags, seedlings), processing (machinery, energy) and overheads respectively. Consequently, if the prices of these inputs are largely determined at the economy wide level and mostly responsive to macroeconomic policies and the exchange rate then the evolution of input costs are independent of liberalisation. It would then be reasonable to argue that there are no input cost implications to liberalisation and that the benefits to producers in terms of revenue outlined above correspond to the total benefits to producers. ${ }^{23}$

22. The lack of input cost data may be overcome in the near future. In April 2010 the Executive Director of the International Coffee Council asked all members of the organisation to provide input cost data for crop years 2000/01 to 2009/10. See ICO (2010).

23. We have not come across any studies showing that liberalisation has increased input costs. It is possible that input costs after liberalisation increased faster than revenues because of factors other than liberalisation. However, producers are still better off after liberalisation (due to the higher revenues) because without liberalisation they would have been even worse off financially. 


\section{Conclusion and Policy Implications}

This paper argues that to understand the dynamics of coffee prices we need to allow for structural breaks in the equilibrium coffee price ratio due to changes in government policies. To simply undertake the standard analysis ignoring the breaks is inadequate. In contrast, estimating the model allowing for the shifts in the coffee price ratio as reported in Table 4 provides estimates that are consistent with our understanding of coffee markets. First, terminal and producer prices move closely together in equilibrium. Second, shocks to the relationship between the two coffee prices are eradicated very quickly. Third, liberalisation of the coffee markets has coincided with increases in the coffee price ratio which is equivalent to the producers' share of the terminal price of coffee. In Brazil, the equilibrium share has risen from 0.6254 in the late 1980 s to 0.8461 in the most recent period up to October 2007. Over the same period the equilibrium share to producers has increased from 0.6325 to 0.7896 for Guatemala and from 0.5485 to 0.8494 for India.

The systematic increase in the producers' equilibrium share of terminal coffee prices over the last seventeen years has greatly benefited the producers in these three coffee producing countries. The combination of the increase in the equilibrium producers share and the increase in the real price of coffee after liberalisation beginning in 1990 suggest that the benefit to producers in terms of revenue in 2007 is around 2.15, 0.15 and 0.22 \$US billion for Brazil, Guatemala and India. ${ }^{24}$ This can be compared with the actual payments to coffee producers of 4.63, 0.47 and 0.65 \$US billion in 2007 .

It should be stressed that the analysis does not suggest that liberalisation poses no risk for producers. Instead it gives rise to new problems by exposing producers to the vagaries of the market. In particular, concerns have been raised that liberalisation has exposed producers to the full volatility of

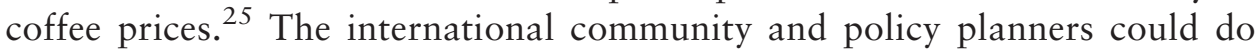
more for producers by helping to develop missing credit and insurance markets so as to handle this increase in volatility. However, leaving aside the issue of what more could be done for producers, this paper emphasises that responding to calls for returning to the kind of interventions that

\footnotetext{
24. The total benefit to producers in 2007 is calculated as: $\left[Q_{2007} \bullet P_{T, 2007} \bullet U_{2007}^{e}\right]-\left[Q_{2007} \bullet \frac{P_{T, 2007}}{\left(1+\delta_{L}\right)^{17}} \bullet U_{1989}^{e}\right]$ where $\left(1+\delta_{L}\right)^{17}$ is the compounded annual real increase in terminal prices during the 17 years of liberalisation. The first component of the calculation is what the producer actually received in 2007. The second component is what the producer would receive if the real terminal price was lower, $\frac{P_{T, 2007}}{\left(1+\delta_{L}\right)^{17}}$, and they only received the 1989 equilibrium producers share, $U_{1989}^{e}$. The difference between the two components is the benefit to producers from higher real coffee prices and a higher equilibrium share of terminal prices. This measure of the benefit assumes that the quantity of coffee produced has been unaffected by the liberalisation of the coffee markets. Alternatively, if coffee output has increased since liberalisation then our estimate understates the 'true' benefit to producers.
}

25. For example see Gemech et al. (2011). 


\section{existed prior to the liberalisation of coffee markets is not in the interest of producers.}

\section{REFERENCES}

ActionAid, 2008. Commodity Dependence and Development: Suggestions to Tackle the Commodities Problem. Report prepared for the ActionAid and the South Centre, April, Johannesburg and Geneva.

Akiyama, T., 2001. Coffee Market Liberalization since 1990. In: T. Akiyama, J. Baffles, D.F. Larson, and P. Varangis Eds., Commodity Market Reforms: Lessons of Two Decades, World Bank, Washington DC.

Akiyama, T., J. Baffes, D. Larson, and P. Varangis, 2001. Market Reforms: Lessons from Country and Commodity Experiences. In: T. Akiyama, J. Baffles, D.F. Larson, and P. Varangis Eds., Commodity Market Reforms: Lessons of Two Decades, World Bank, Washington DC.

Alizadeh, A., and N. Nomikos, 2005. Agricultural Reforms and the Use of Market Mechanisms for Risk Management. Report prepared for the Futures and Options Association, London.

Anderson, K., M. Kurzweil, W. Martin, D. Sandri, and E. Valenzuela, 2008. Measuring Distortions to Agricultural Incentives Revisited, World Trade Review, vol. 74, pp. 675-704.

Ardeni, P.G., 1989. Does the Law of One Price Really Hold for Commodity Prices? American Journal of Agricultural Economics, vol. 71, pp. 303-28.

Baffes, J., 1991. Some Further Evidence on the Law of One Price, American Journal of Agricultural Economics, vol. 4, pp. 21-37.

Bai, J., and P. Perron, 1998. Estimating and Testing Linear Models with Multiple Structural Changes. Econometrica, vol. 66, pp. 47-78.

Bates, R.F., 1997. Open Economy Politics: the Political Economy of the World Coffee Trade, Princeton University Press, Princeton.

Batista, J.C., and G.B da Silveira, 2010. Trade Costs and Deviations from the Law of One Price, American Journal of Agricultural Economics, vol. 92, pp. 1011-23.

Calfat, G., and R. Flores, 2002. Government Actions to Support Coffee Producers - an Investigation of Possible Measures from the European Union Side. Economics working paper, vol. 448. Getulio Vargas Foundations, Brazil.

Daviron, B., and S. Ponte, 2005. The Coffee Paradox: Global Markets, Commodity Trade and the Elusive Promise of Development. Zed Books, London.

Enke, S., 1951. Equilibrium among Spatially Separated Markets: Solution by Electrical Analogue, Econometrica, vol. 191, pp. 40-47.

Fitter, R., and R. Kaplinsky, 2001. Who Gains from Product Rents as the Coffee Market becomes more Differentiated? A Value Chain Analysis, IDS Bulletin Paper, May 2001, University of Sussex, UK.

Fortenbery, R., and H. Zapta, 2004. Developed Speculation and Underdeveloped Markets - the Role of Futures Trading on Export Prices in Less Developed Countries', European Review of Agricultural Economics, vol. 314, pp. 451-71.

Gemech, F., S. Mohan, A. Reeves, and J. Struthers, 2011. Market-based Price-Risk Management: Welfare Gains for Coffee Producers from Efficient Allocation of Resources. Oxford Development Studies, vol. 39, no. 1, pp. 49-68.

Gilbert, C., 1996. International Commodity Agreements: An Obituary Notice, World Development, vol. 241, pp. 1-19.

ICO, 1989. Agreement: Renegotiation of the International Coffee Agreement, Outline Joint Approach for Implementing the Universal Quota Concept, ICC 51/5 E 4/6, International Coffee Organization, London.

ICO, 1996/1997. Coffee Market Studies: India, International Coffee Organization, London.

_ 2007. Coffee Statistics, International Coffee Organization, London. 
2010. Production Costs, ICC 105-6, International Coffee Council, 105th Session 22 - 24 September 2010, International Coffee Organization, London.

Jarvis, L.S., 2005, The Rise and Decline of Rent-Seeking Activity in the Brazilian Coffee Sector: Lessons from the Imposition and Removal of Coffee Export Quotas, Working Paper No. 04-004, Department of Agricultural and Resource Economics and the Giannini Foundation, University of California, California, USA.

Jerome, A., and O. Ogunkola, 2000. Characteristics and Behavior of African Commodity/Product Markets and Market Institutions and their Consequences for Economic Growth. CID Working Papers 35, Center for International Development, Harvard University, USA.

Krivonos, E., 2004. The Impact of Coffee Market Reforms on Producer Prices and Price Transmission, Policy Research Working Paper No. 3358, July, World Bank, Washington DC.

McIntire, J., and P. Varangis, 1999. Reforming Cote d'Ivoire's Cocoa Marketing and Pricing System, Policy Research Working Paper No. 2081, March, World Bank, Washington DC.

Mehta, A., and J-P. Chavas, 2008. Responding to the Coffee Crisis: What can we Learn from Price Dynamics? Journal of Development Economics, vol. 85, pp. 282-311.

Michael, P., A.R. Nobay, and D. Peel, 1994. Purchasing Power Parity Yet Again: Evidence from Spatially Separated Commodity Markets, Journal of International Money and Finance, vol. 136, pp. 637-57.

Mohan, S., 2007. Market-based Price-risk Management for Coffee Producers, Development Policy Review, vol. 253, pp. 333-54.

Mundlak, Y., and D.F. Larson, 1992. On the Transmission of World Agricultural Prices, The World Bank Economic Review, vol. 6, pp. 399-422.

Oxfam, 2002 Mugged: Poverty in your Coffee Cup, Oxfam, Oxford.

Perron, P., 1989. The Great Crash, the Oil Price Shock, and the Unit Root Hypothesis, Econometrica, vol. 57, no. 6, November, pp. 1361-401.

Ponte, S., 2002. The 'Latte Revolution'? Regulation, Markets and Consumption in the Global Coffee Chain. World Development, vol. 30, pp. 1099-122.

Raffaeli, M., 1995. Rise and Demise of Commodity Agreements: An Investigation into the Breakdown of International Commodity Agreements, Woodhead Publishing, Cambridge, UK.

Rapsomanikis, G., D. Hallam, and P. Conforti, 2004. Market Integration and Price Transmission in Selected Food and Cash Crop Markets of Developing Countries: Review and Applications, Commodity Market Review 2003-2004, Food and Agricultural Organisation, Rome.

Samuelson, P.A., 1952. Spatial Price Equilibrium and Linear Programming, American Economic Review, vol. 42, pp. 560-80.

1957. Intertemporal price equilibrium. Welwirtschaftliches Archiv, Band, 79, pp. 181-221.

Shepherd, B., 2004. Market Power in International Commodity Processing Chains: Preliminary Results from the Coffee Market. GEM, Sciences-Po, Paris.

South Centre, 2008. From Declaration to Action on Commodities: Making the Turning Point at UNCTAD X11, Policy Brief 14, South Centre, Geneva.

Takayama, T., and G.G. Judge, 1971. Spatial and Temporal Price Allocation Models, Amsterdam, North Holland.

Talbot, J.M., 2004. Grounds for Agreement: the Political-Economy of the Coffee Commodity Chain. Rowman and Littlefield, Oxford.

Varangis, P., D. Larson, and J.R. Anderson, 2002. Agricultural Markets and Risks - Management of the Latter, not the Former, Policy Research Paper No. 2793, World Bank, Washington DC.

Vataja, J., 2000. Should the Law of One Price be Pushed Away? Evidence from International Commodity Markets, Open Economies Review, vol. 11, pp. 399-415.

Winter-Nelson, A., and A. Temu, 2002. Institutional Adjustment and Transaction Costs: Product and Input Markets in the Tanzanian Coffee System, World Development, vol. 304, pp. 561-74. 